\title{
62. An Enzymic Transcarboligation
}

\author{
By Shiro AKabori, Yuichi Yamamura, Tuneo Okuyama, \\ Shigeo IKUTA, and Yoshiharu IzUMr \\ Laboratory of Biochemistry, Faculty of Science, Osaka University, \\ and Toneyama Hospital, Osaka \\ (Comm. By R. Majima, M.J.A., June 12, 1953)
}

In their recent communication on the biochemical rôle of acetoindiacetyl system, Akabori and Shimazu ${ }^{1)}$ supposed that the enzymic formation of acetoin and acetic acid from diacetyl and acetaldehyde, which is apparently an oxido-reduction, is actually a transcarboligation, i. e. an exchange reaction between an acetyl group of diacetyl and acetaldehyde molecule as follows:

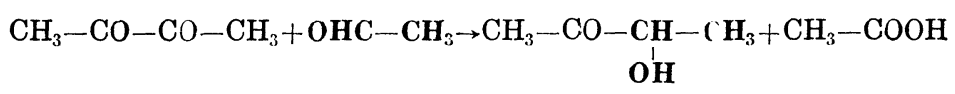

The purpose of the present work is to confirm the supposed mechanism using $\mathrm{C}^{14}$ labelled acetaldehyde and unlabelled diacetyl as substrates.

Enzyme preparation : Fresh pig heart mince was homogenized in a $\beta$-glycerophosphate buffer by a glass homogenizer and centrifuged. The cloudy supernatant was brought to $\mathrm{pH} 4.6$ by adding $10 \%$ acetic acid. The precipitate thereby formed was centrifuged down and suspended in phosphate buffer ( $\mathrm{pH}$ 7.4). This enzyme preparation has the diacetyl-mutase ${ }^{2)}$ activity dismutating diacetyl to acetoin and acetic acid in the anaerobic condition in the presence of cocarboxylase and $\mathrm{Mn}^{++}$.

Diacetyl : Commercial diacetyl was purified by distillation and the fraction boiling at $87.5-88^{\circ}$ was used.

Acetaldehyde-1,2-C $\mathrm{C}^{14}$ : Acetylene-C $\mathrm{C}^{14}$ was evolved from barium carbide- $\mathrm{C}^{14}$, converted to acetaldehyde using mercuric sulfate as catalyser and purified by distillation. 10,266 c.p.m./mM.

\section{Experiments}

$5 \mathrm{mM}$ of unlabelled diacetyl and $5.11 \mathrm{mM}$ of acetaldehyde-C $\mathrm{C}^{14}$ were added to $100 \mathrm{ml}$ of the enzyme preparation containing $\mathrm{Mn}^{++}$and cocarboxylase and incubated at $37.5^{\circ}$, air in the gas phase being replaced by nitrogen. After 4.5 hours incubation the reaction mixture was acidified by adding $3 \mathrm{~N} \mathrm{H}_{2} \mathrm{SO}_{4}$, heated to $60^{\circ}$, unchanged diacetyl and acetaldehyde were removed by airation and finally distilled with $\mathrm{FeCl}_{3}$. Diacetyl in the distillate was precipitated as Ni-dimethylglyoxime by usual method. The precipitate was collected 
and its radioactivity was measured by a Geiger-Müller end window counter. In the control experiment labelled acetaldehyde only was incubated with the same enzyme preparation.

In the both experiments reaction vessels contained $100 \mathrm{ml}$ of enzyme preparations, $2.5 \mathrm{mg}$ of cocarboxylase, $10 \mathrm{mg}$ of $\mathrm{MnCl}_{2}$ and the substrates as shown in the following table.

\begin{tabular}{|c|c|c|c|}
\hline Substrate & Acetoin formed & Total activity & Specific activity \\
\hline I. Acetaldehyde $\mathrm{C}^{14} 5.11^{\mathrm{mM}}$ & $1.57^{\mathrm{mg}}$ & $11,773^{\text {c.p.m. }}$ & $\begin{array}{c}\text { c.p.m.m./mM } \\
7,500\end{array}$ \\
\hline Diacetyl & & & \\
\hline II. Acetaldehyde C14 5.11 & 0.29 & 5,635 & 19,431 \\
\hline
\end{tabular}

It is obvious from the above figures that the total yield and the total activity of acetoin in exp. I is much higher as compared to the control experiment. From these results it could be concluded that the larger part of acetoin in the exp. I has been produced not by the oxido-reduction but by the transcarboligation.

\section{References}

1) S. Akabori and Y. Shimazu: Proc. Japan Acad., 28, 36 (1952).

2) D. E. Green, P.K. Stumpf, and K. Zarudnaya : J. Biol. Chem., 167, 811 (1947). 